\title{
UV photo-detector based on p-NiO thin film/n- ZnO nanorods heterojunction prepared by a simple process
}

\begin{abstract}
Ahmad Echresh, Chan Oeurn Chey, Morteza Zargar Shoushtari, Volodymyr Khranovskyy, Omer Nour and Magnus Willander
\end{abstract}

\section{Linköping University Post Print}

\section{Tweet}

N.B.: When citing this work, cite the original article.

Original Publication:

Ahmad Echresh, Chan Oeurn Chey, Morteza Zargar Shoushtari, Volodymyr Khranovskyy, Omer Nour and Magnus Willander, UV photo-detector based on $\mathrm{p}-\mathrm{NiO}$ thin film/n-ZnO nanorods heterojunction prepared by a simple process, 2015, Journal of Alloys and Compounds, (632), 165-171.

http://dx.doi.org/10.1016/j.jallcom.2015.01.155

Copyright: Elsevier http://www.elsevier.com/

Postprint available at: Linköping University Electronic Press http://urn.kb.se/resolve?urn=urn:nbn:se:liu:diva-116939 


\title{
UV photo-detector based on p-NiO thin film/n-ZnO nanorods heterojunction prepared by a simple process
}

\author{
Ahmad Echresh a,b ${ }^{\text {, }}$ Chan Oeurn Chey ${ }^{\mathrm{a}}$, Morteza Zargar Shoushtari ${ }^{\mathrm{b}}$, Volodymyr Khranovskyy ${ }^{\mathrm{c}}$, \\ Omer Nur $^{\mathrm{a}}$ and Magnus Willander ${ }^{\mathrm{a}}$ \\ ${ }^{a}$ Department of Science and Technology, Physical Electronics and Nanotechnology Division, Campus \\ Norrköping, Linköping University, SE-601 74 Norrköping, Sweden \\ ${ }^{b}$ Department of Physics, Shahid Chamran University of Ahvaz, Ahvaz, Iran \\ c Department of Physics, Chemistry and Biology (IFM), Linköping University, SE-5818358183 \\ Linköping, Sweden
}

Corresponding author e-mail: $\underline{\text { ahmadechresh@gmail.com }}$

\begin{abstract}
A UV photo-detector based on $\mathrm{p}-\mathrm{NiO}$ thin film $/ \mathrm{n}-\mathrm{ZnO}$ nanorods heterojunction was fabricated using a simple two-step fabrication process. The aqueous chemical hydrothermal and thermal evaporation methods were combined to grow the $\mathrm{ZnO}$ nanorods and the $\mathrm{NiO}$ thin film, respectively. Structural investigation indicated that well aligned $\mathrm{ZnO}$ nanorods with hexagonal face having a preferential orientation along the c-axis (002) have been achieved and that the $\mathrm{NiO}$ thin film is covering all the $\mathrm{ZnO}$ nanorods. X-ray photoelectron spectroscopy (XPS) was used to investigate the band alignment of the heterojunction and the valence and the conduction band offsets were determined to be $1.50 \mathrm{eV}$ and $1.83 \mathrm{eV}$, respectively. The current-voltage characteristics of the $\mathrm{p}-\mathrm{NiO}$ thin film/ZnO nanorods heterojunction showed a clear rectifying behavior under both dark and UV illumination conditions. The response of the heterojunction diode was excellent regarding the photocurrent generation. Although other similar heterojunction diodes demonstrated lower threshold voltage, the rectification ratio and the sensitivity of the fabricated diode were superior in comparison to other similar heterojunctions reported recently, implying the vitality of the presented two-step process.
\end{abstract}

Keywords: $\mathrm{ZnO}$ nanorods, $\mathrm{NiO}$ thin film, UV photo-detector, Heterojunction. 


\section{Introduction}

Zinc oxide $(\mathrm{ZnO})$ heterojunctions based ultraviolet (UV) detectors have attracted considerable attention in comparison to those made from other semiconductors such as $\mathrm{Si}, \mathrm{SiC}$ and AlGaN [1-4]. Due to its wide direct band gap energy (3.37 eV), relatively large exciton binding energy (60 meV at room temperature) and excellent optical and electrical properties, $\mathrm{ZnO}$ has been recognized as a promising material for UV detector [5-7]. Ultra violet detection by $\mathrm{ZnO}$ is based on strong oxygen chemisorptions and photodesorption mechanism on the surface and for efficient UV detection high quality $\mathrm{ZnO}$ heterojunctions are needed [8]. So far $\mathrm{ZnO}$ based UV photo-detectors with high performance have been reported using different methods such as molecular beam epitaxy [9] and sol-gel [10]. Recently, it has been reported that hybrid structures of $\mathrm{ZnO}$ with other semiconductors could increase the performance of UV detectors [11-14]. On the other hand, nickel oxide (NiO) has been under investigation for different technological applications due to its wide direct band gap $(3.6-4.0 \mathrm{eV})$ and it is intrinsically $\mathrm{p}$ type semiconductor. These properties make $\mathrm{NiO}$ a suitable candidate for the fabrication of $\mathrm{p}$ $\mathrm{NiO} / \mathrm{n}-\mathrm{ZnO}$ heterojunction based UV photo-detectors [15-18]. Alternative inexpensive fabrication techniques are usually needed to realize large scale, mass production and low cost UV photo-detectors with high performance. Until now there are only few reports about using the thermal evaporation method for the synthesis of $\mathrm{NiO}$ thin film [19]. Moreover, there has been no detailed investigation reported about using this method to fabricate $\mathrm{p}-\mathrm{NiO}$ thin film/n- $\mathrm{ZnO}$ nanorods heterojunction based UV photo-detector with high quality.

In the present study, we have synthesized the $\mathrm{NiO}$ thin film using thermal evaporation method to fabricate $\mathrm{p}-\mathrm{NiO}$ thin film $/ \mathrm{n}-\mathrm{ZnO}$ nanorods heterojunction. The materials were characterized by X-ray diffraction (XRD), field emission scanning electron microscope (FESEM) and photoluminescence (PL). The current-voltage characteristics were investigated under UV illumination via semiconductor parameter analyzer and potentiostat. Further, the obtained results were compared to those achieved from other UV photodetectors based on the similar heterojunction grown by other methods. 


\section{Experimental}

\subsection{Growth of $\mathrm{ZnO}$ nanorods}

Commercially available fluorine doped tin oxide (FTO) glass substrate was used in this study and all the chemicals were of analytical grade and were purchased from Sigma Aldrich. The FTO glass substrate was cleaned by sonication in acetone, deionized water, and isopropanol, respectively. Part of the substrate at the edge was covered with scotch tape in order to have a metal contact area. Then the substrate preparation technique developed by Green et al. [20] was used to improve the quality of the grown $\mathrm{ZnO}$ nanorods. To grow the $\mathrm{ZnO}$ nanorods, an equimolar concentration of hexamethylenetetramine (HMT) and zinc nitrate hexahydrate solutions $(0.075 \mathrm{M})$ were separately prepared and mixed together. Then the final solution was poured into a beaker and the pretreated substrate was immersed in the solution with the growth side facing downward. Then the beaker was sealed and heated in a laboratory oven at $95{ }^{\circ} \mathrm{C}$ for 5 hours and then it was allowed to cool down at room temperature. After the growth process, the sample was rinsed with deionized water to remove the residual salts and dried with nitrogen blow.

\subsection{Synthesis of the $\mathrm{NiO}$ thin film/ZnO nanorods heterojunction}

To fabricate the $\mathrm{p}-\mathrm{NiO}$ thin film/n-ZnO nanorods heterojunction, $\mathrm{Ni}$ film with $50 \mathrm{~nm}$

thickness was deposited by thermal evaporation in a vacuum chamber with a pressure of $2 \times 10^{-6}$ mbar on the top of $\mathrm{ZnO}$ nanorods. Then to oxidize the $\mathrm{Ni}$ film, the sample was annealed in oxygen ambient at a temperature of $400{ }^{\circ} \mathrm{C}$ for 5 hours. To prepare the UV detector device, $\mathrm{Ag}$ circular contact with $80 \mathrm{~nm}$ thickness and $1 \mathrm{~mm}$ diameter was afterwards deposited on top of the $\mathrm{NiO}$ thin film using the thermal evaporation method.

\subsection{Characterization}

The structural and morphological properties of the $\mathrm{p}-\mathrm{NiO} / \mathrm{n}-\mathrm{ZnO}$ heterojunction were examined by X-ray diffraction (XRD: Phillips PW 1729 powder diffractometer using $\mathrm{CuK} \alpha$ radiation), field emission scanning electron microscope (FESEM: LEO 1550 Gemini) and X-ray photoelectron spectroscopy (XPS: ESCA200 spectrometer in ultrahigh vacuum with a base pressure of $10^{-10}$ mbar). The light emission features of the samples were studied by a microphotoluminescence $(\mu \mathrm{PL})$ setup at room temperature. The excitation was performed by a 
frequency doubled Nd:YVO laser as a continuous wave excitation source, giving a wavelength of $\lambda=266 \mathrm{~nm}$. The UV detection characteristics were evaluated by semiconductor parameter analyzer and potentiostat (Autolab) under lamp illumination at $\lambda_{\max }=365 \mathrm{~nm}$ with a light power of $18 \mathrm{~W}$.

\section{Results and discussion}

\subsection{Morphological and structural properties}

Typical top view and cross-section SEM images of the $\mathrm{ZnO}$ nanorods and the $\mathrm{NiO}$ thin film grown on the top of the $\mathrm{ZnO}$ nanorods are shown in Figure 1(a-d). It is clearly seen that a relatively well aligned $\mathrm{ZnO}$ nanorods having hexagonal faces with an average diameter and height of approximately $100 \mathrm{~nm}$ and $1 \mu \mathrm{m}$, respectively were achieved. Also, as it can be seen that the $\mathrm{NiO}$ thin film covers all the $\mathrm{ZnO}$ nanorods with relatively smooth surface. In order to verify the crystal structure of the materials forming the heterojunction, XRD analysis was performed. Figure 2 (a) shows the XRD patterns of the FTO glass substrate, NiO thin film/FTO and $\mathrm{NiO}$ thin film/ZnO nanorods/FTO heterojunction. It can be observed that the XRD pattern displays diffraction peaks that corresponds to $\mathrm{ZnO}$ wurtzite structure (JCPDS No. 36-1451) and that the $\mathrm{ZnO}$ has a preferential orientation along the c-axis since the (002) peak is clearly seen to be the highest in intensity. The lattice constants for the $\mathrm{ZnO}$ calculated from the XRD data were $a=3.25 \AA$ and $c=5.20 \AA$. Also, the XRD patterns show the characteristic peaks of $\mathrm{NiO}$ which correspond to the (111) and the (200) planes of cubic NiO structure consistent with diffraction file (JCPDS No. 01-1239). The lattice constant of the grown $\mathrm{NiO}$ is calculated to be $\mathrm{a}=4.16 \AA$. It should be mentioned that the (111) direction of the $\mathrm{NiO}$ thin film has the same angle with one of the peaks of the FTO glass substrate $\left(2 \theta=37.66^{\circ}\right)$.

\subsection{Optical properties}

Photoluminescence (PL) study is a convenient analysis method to gain useful information about the optical properties of semiconductor materials such as bulk material, thin films or individual nanostructures [21-24]. The PL spectra of the $\mathrm{ZnO}$ nanorods and the $\mathrm{NiO}$ thin film/ZnO nanorods heterojunction are shown in Figure 2 (b). All the spectra were taken at the same excitation power and integration time and are therefore comparable. It can be seen that the 
ultraviolet (UV) emission which is called near band edge emission (NBE) and the deep level emission (DLE) peaks are observed for $\mathrm{ZnO}$ nanorods centred approximately at $375 \mathrm{~nm}, 520 \mathrm{~nm}$ (DLE1, green emission) and $680 \mathrm{~nm}$ (DLE2, red emission), respectively. The UV emission is attributed to the recombination of free excitons and the green and red peaks are ascribed to the recombination between the conduction band and zinc interstitial $\left(\mathrm{Zn}_{\mathrm{i}}\right)$ energy level to oxygen vacancy $\left(\mathrm{V}_{\mathrm{O}}\right)$ and oxygen interstitial $\left(\mathrm{O}_{\mathrm{i}}\right)$, respectively $[25,26]$. The PL emission intensity of the $\mathrm{NiO}$ thin film/ZnO nanorods heterojunction sample is lower in intensity compared to that of the pure $\mathrm{ZnO}$ nanorods. This can be explained by possible absorption of the PL signal by the top $\mathrm{NiO}$ layer. This effect was particularly prominent for the defect luminescence range, namely DLE1 and DLE2.

\subsection{Band alignment of the $\mathrm{NiO}$ thin film/ZnO nanorods heterojunction}

Three samples have been prepared to measure the valence band offset in the $\mathrm{NiO}$ thin film/ZnO nanorods heterojunction using X-ray photoelectron spectroscopy (XPS). ZnO nanorods were grown on the bare FTO substrate (sample 1) and $\mathrm{NiO}$ with $50 \mathrm{~nm}$ thickness were deposited on the another bare FTO substrate (sample 2) then $\mathrm{NiO}$ with $10 \mathrm{~nm}$ thickness deposited on the grown $\mathrm{ZnO}$ nanorods (sample 3). The core levels (CLs) and valence band (VB) edge XPS spectra of $\mathrm{ZnO}$ (sample 1) and $\mathrm{NiO}$ (sample 2) are shown in Figure 3(a-d) and Figure 4(a, b), respectively. All the CL XPS peaks have been fitted using Touguard background and Voigt profile. As shown in Figure 3(a), the binding energy peak at $1022.34 \pm 0.05 \mathrm{eV}$ which corresponds to the core level of the $\mathrm{Zn} 2 \mathrm{p}_{3 / 2}$ has a symmetric shape and is attributed to the $\mathrm{Zn}-\mathrm{O}$ band. The CL XPS spectrum of the Ni 2p $3 / 2$ consists of three components located at $853.65 \pm$ $0.05 \mathrm{eV}, 855.38 \pm 0.05 \mathrm{eV}$ and $860.92 \pm 0.05 \mathrm{eV}$ which all ascribed to Ni-O band [27]. The $\mathrm{O} 1 \mathrm{~s}$ peak of the $\mathrm{ZnO}$ and the $\mathrm{NiO}$ observed around $531.08 \pm 0.05 \mathrm{eV}$ and $529.32 \pm 0.05 \mathrm{eV}$ could be assigned to $\mathrm{O}^{2-}$ ions in the $\mathrm{ZnO}$ and the $\mathrm{NiO}$ lattice array and the shoulder peaks around $532.27 \pm$ $0.05 \mathrm{eV}$ and $530.92 \pm 0.05 \mathrm{eV}$ can be attributed to defect sites such as $\mathrm{O}_{2}$ on the $\mathrm{ZnO}$ and on the $\mathrm{NiO}$ surfaces [28]. The valence band maximum (VBM) of the $\mathrm{ZnO}$ nanorods and the $\mathrm{NiO}$ thin film measured from the VB spectra using linear fitting were $3.04 \pm 0.05 \mathrm{eV}$ and $0.61 \pm 0.05 \mathrm{eV}$, respectively. The core levels of the $\mathrm{Zn} 2 \mathrm{p}_{3 / 2}$ and $\mathrm{Ni} 2 \mathrm{p}_{3 / 2}$ in the $\mathrm{NiO} / \mathrm{ZnO}$ heterojunction (sample 3) which are shown in Figure 5(a, b) are located at $1021.83 \pm 0.05 \mathrm{eV}, 854.07 \pm 0.05 \mathrm{eV}, 855.74$ 
$\pm 0.05 \mathrm{eV}$ and $861.27 \pm 0.05 \mathrm{eV}$, respectively. As it can be seen the $\mathrm{Zn} 2 \mathrm{p}_{3 / 2}$ and the Ni $2 \mathrm{p}_{3 / 2}$ peaks in the $\mathrm{NiO} / \mathrm{ZnO}$ heterojunction have a little shift. The experimentally observed values of peak positions and the VBM are given in Table 1. The valence band offsets of the NiO thin film/ZnO nanorods heterojunction were measured using the following equation [27, 29]:

$$
\Delta \mathrm{E}_{\mathrm{V}}=\left(E_{N i 2 p}^{N i O}-E_{V B M}^{N i O}\right)-\left(E_{Z n 2 p}^{Z n O}-E_{V B M}^{Z n O}\right)+\Delta \mathrm{E}_{\mathrm{CL}}
$$

where $\left(E_{N i 2 p}^{N i O}-E_{V B M}^{N i O}\right)$ is the energy difference between the Ni 2p $3 / 2$ and the VBM in the NiO thin film (sample 2), $\left(E_{Z n 2 p}^{Z n O}-E_{V B M}^{Z n O}\right)$ is the energy difference between the $\mathrm{Zn} 2 \mathrm{p}_{3 / 2}$ and the VBM in the $\mathrm{ZnO}$ nanorods (sample 1), $\Delta \mathrm{E}_{\mathrm{CL}}=\left(E_{Z n 2 p}^{Z n O}-E_{N i 2 p}^{N i O}\right)$ is the energy difference between the $\mathrm{Zn}$ $2 \mathrm{p}_{3 / 2}$ and the $\mathrm{Ni} 2 \mathrm{p}_{3 / 2}$ core levels in the $\mathrm{NiO}$ thin film/ $\mathrm{ZnO}$ nanorods heterojunction (sample 3 ). Also, the conduction band offset of the heterojunction can be measured using following equation $[27,29]$ :

$$
\Delta \mathrm{E}_{\mathrm{C}}=E_{g}^{N i O}-E_{g}^{Z n O}+\Delta \mathrm{E}_{\mathrm{V}}
$$

The band gaps of $\mathrm{ZnO}$ and $\mathrm{NiO}$ are $3.37 \mathrm{eV}$ and $3.70 \mathrm{eV}$ at room temperature, respectively. Therefore, the measured $\Delta \mathrm{E}_{\mathrm{V}}$ and $\Delta \mathrm{E}_{\mathrm{C}}$ are found to be $1.50 \mathrm{eV}$ and $1.83 \mathrm{eV}$, respectively, which are very close to the values reported by Zhi Guo Yang et al. [29]. The schematic band alignment of the $\mathrm{NiO}$ thin film/ZnO nanorods heterojunction is shown in Figure 6. It can be seen that a type-II band alignment is formed at the interface of the heterojunction.

\subsection{Electrical properties}

Figure 7 (a) shows the schematic diagram of the $\mathrm{p}-\mathrm{NiO}$ thin film $/ \mathrm{n}-\mathrm{ZnO}$ nanorods heterojunction. Figure 7 (b) displays the typical observed current density - voltage (J-V) and the semilog $\mathrm{J}-\mathrm{V}$ characteristics of the $\mathrm{p}-\mathrm{NiO} / \mathrm{n}-\mathrm{ZnO}$ heterojunction in the dark and under $\mathrm{UV}$ illumination at room temperature. As it can be seen the diode shows an obvious rectifying behavior under both dark and UV illuminated condition. The electrical parameters of the p-NiO thin film/n-ZnO nanorods heterojunction in dark and under UV illumination conditions are listed in Table 2. The turn-on voltage of the diode exhibits a relatively low value indicating that the diode has fairly low power consumption. The high value of the $\mathrm{I}_{\mathrm{F}} / \mathrm{I}_{\mathrm{R}}$ ratio in dark condition 
displays the high quality of the heterojunction, where $I_{F}$ and $I_{R}$ is the current under forward bias and reverse bias $(7 \mathrm{~V})$, respectively. To evaluate the ideality factor of the diode, the dark current - voltage (I-V) response of the diode in low bias region can be modeled using the ideal diode equation [14]:

$$
\mathrm{I}=\mathrm{I}_{\mathrm{sat}}[\exp (\mathrm{V} / \mathrm{nkT})-1]
$$

where $\mathrm{I}_{\text {sat }}$ is the reverse bias saturation current, $\mathrm{V}$ is the applied voltage, $\mathrm{n}$ is the ideality factor, $\mathrm{k}$ is the Boltzmann's constant and $\mathrm{T}$ is the temperature. The ideality factor (n) and the reverse bias saturation current $\left(\mathrm{I}_{\mathrm{sat}}\right)$ can be calculated from the slope and intercept of the straight line region of the forward bias in $\ln (\mathrm{I})-\mathrm{V}$ plot, as shown in the Figure 7 (c). These parameters are listed in Table 2. The ideality factor of the diode is much larger than the value of an ideal diode $(n=1)$. Such a high value of $\mathrm{n}$ suggests that the transport mechanism is not dominated by the thermionic emission, but consisting of other mechanisms like defect assisted tunnelling with conventional electron-hole recombination [30]. A potentiostat was used to check the decay time response of the diode. The UV illumination was applied for $13 \mathrm{~s}$ and the gap between the UV illuminations to bring the diode at stable position was about $40 \mathrm{~s}$ as shown in Figure 7(d). It can be seen that the average decay time response of the diode is about $25 \mathrm{~s}$. To understand the origin of the photocurrent probing the adsorption and desorption of oxygen from the $\mathrm{ZnO}$ surface under UV illumination is to be understood. In the present work, the $\mathrm{NiO}$ is prepared by annealing the $\mathrm{Ni}$ in oxygen ambient, therefore oxygen molecules are adsorbed onto the $\mathrm{ZnO}$ nanorods surface (Figure 3c) by capturing free electrons from the $\mathrm{n}-\mathrm{ZnO}$ nanorods $\left[\mathrm{O}_{2}(\mathrm{~g})+\mathrm{e}^{-} \rightarrow \mathrm{O}_{2}^{-}\right]$where a depletion layer will be formed near the interface of the p-NiO/n- $\mathrm{ZnO}$ heterojunction [13, 31-34]. Under UV illumination, more electron-hole pairs will be generated in the p-NiO thin film and due to the lower valence band offset compared to the conduction band offset; holes will be transferred from the $\mathrm{NiO}$ towards the $\mathrm{ZnO}$. Then this will be followed by holes migration to the surface of the $\mathrm{ZnO}$ nanorods along the potential gradient, produced by band bending, discharging the negatively charged adsorbed oxygen ions $\left[\mathrm{O}_{2}^{-}+\mathrm{h}^{+} \rightarrow \mathrm{O}_{2}(\mathrm{~g})\right]$. Then, oxygen is desorbed from the surface, resulting in an increase in the free carrier concentration and a decrease in the width of the depletion layer [13, 31-33]. This leads to an increase in the carrier injection, producing a persistent photocurrent. 
As can be seen from Table 2, under UV illumination a relatively high $\mathrm{I}_{\mathrm{F}} / \mathrm{I}_{\mathrm{R}}$ contrast ratio was observed. The enhancement of $\mathrm{I}_{\mathrm{F}} / \mathrm{I}_{\mathrm{R}}$ ratio compared to the dark ratio is about $57 \%$ and it is revealing that the response of the present heterojunction diode is excellent in generating photocurrent in comparison to previous reports on similar heterojunctions prepared by different methods $[8,13,18]$. Much Lower current contrast ratio, i.e. low sensitivity to UV, was observed from similar thin film heterojunction prepared by r.f. sputtering [18]. The low sensitivity was attributed to the high density of interface traps. Using the low temperature chemical growth for decorating $\mathrm{ZnO}$ nanorods with $\mathrm{NiO}$ coral-reef like forming a heterojunction that was tested for UV detection was performed recently in our group [13]. Again, the present approach indicated that it provides a better diode performance and hence a better UV sensitivity.

\section{Conclusion}

In summary, $\mathrm{p}-\mathrm{NiO}$ thin film/n- $\mathrm{ZnO}$ nanorods heterojunction was fabricated. The $\mathrm{p}$ $\mathrm{NiO} / \mathrm{n}-\mathrm{ZnO}$ heterojunction showed an obvious rectifying behavior and the response of the diode was excellent in generating photocurrent upon UV illumination. X-ray photoelectron spectroscopy results show that the heterojunction has type-II band alignment with a valence band offsets of $1.50 \mathrm{eV}$ and conduction band offset of $1.83 \mathrm{eV}$. The average decay time response of the diode was about $25 \mathrm{~s}$. The PL emission intensity of the $\mathrm{NiO}$ thin film/ZnO nanorods heterojunction sample was lower than those of pure $\mathrm{ZnO}$ nanorods which can be explained by possible absorption of the PL signal by the top NiO layer. The sensitivity and the diode electrical rectification ratio presented here were superior to those achieved from similar heterojunctions prepared by different methods. The demonstrated two step process represents an alternative inexpensive fabrication technique suitable to realize large scale mass production with low cost of $\mathrm{p}-\mathrm{NiO}$ thin film/n-ZnO nanorods UV photo-detectors with high performance. Moreover, with more optimization the present two-step process can yield more efficient heterojunction with improved characteristics. 


\section{Acknowledgement}

The authors acknowledge Linkoping University and Shahid Chamran university of Ahvaz for financial support of this work. Authors would like to acknowledge Prof. P. O. Holtz and M. O. Eriksson for providing the possibility for photoluminescence measurements.

\section{References}

[1] G. Mazzeo, J.L. Reverchon, G. Conte, A. Dussaigne, J.Y. Duboz, Dynamics of AlGaN based detectors in the deep-UV, Solid State Electron 52 (2008) 795-800.

[2] R. Gharbi, M. Abdelkrim, M. Fathallah, E. Tresso, S. Ferrero, C.F. Pirri, T. Mohamed Brahim, Observation of negative capacitance in a-SiC:H/a-Si:H UV photodetectors, Solid State Electron 50 (2006) 367-371.

[3] H. Morkoc, A.D. Carlo, R. Cingolani, GaN-based modulation doped FETs and UV detectors, Solid State Electron 46 (2002) 157-202.

[4] L. van Schalkwyk, W.E. Meyer, J.M. Nel, F.D. Auret, P.N.M. Ngoepe, Implementation of an AlGaN-based solar-blind UV four-quadrant detector, Physica B 439 (2014) 93-96.

[5] Y. He, W. Zhang, S. Zhang, X. Kang, W. Peng, Y. Xu, Study of the photoconductive ZnO UV detector based on the electrically floated nanowire array, Sensor Actuat A-Phys 181 (2012) 6-12.

[6] L. Guo, H. Zhang, D. Zhao, B. Li, Z. Zhang, M. Jiang, D. Shen, High responsivity ZnO nanowires based UV detector fabricated by the dielectrophoresis method, Sensor Actuat B-Chem 166-167 (2012) 12-16.

[7] A. Ievtushenko, G. Lashkarev, V. Lazorenko, V. Karpina, V. Khranovskyy, L. Kosyachenko, V. Sklyarchuk, O. Sklyarchuk, UV radiation detector based on $\mathrm{ZnO}$, doped by N, Sensor Electron Microsystems Technol 3 (2008) 40-44.

[8] X.L. Zhang, K.S. Hui, K.N. Hui, High photo-responsivity ZnO UV detectors fabricated by RF reactive sputtering, Mater Res Bull 48 (2013) 305-309.

[9] E. Przezdziecka, K. Goscinski, M. Stachowicz, D. Dobosz, E. Zielony, J.M. Sajkowski, M.A. Pietrzyk, E. Płaczek-Popko, A. Kozanecki, Spectrum selective UV detectors from an p$\mathrm{ZnO}$ :As/n-GaN diodes grown by Molecular Beam Epitaxy, Sensor Actuat A-Phys 195 (2013) 27-31. 
[10] Z.Q. Xu, H. Deng, J. Xie, Y. Li, X.T. Zu, Ultraviolet photoconductive detector based on Al doped ZnO films prepared by sol-gel method, Appl Surf Sci 253 (2006) 476-479.

[11] N.H. Al-Hardan, A. Jalar, M.A. Abdul Hamid, L.K. Keng, N.M. Ahmed, R. Shamsudin, A wide-band UV photodiode based on n-ZnO/p-Si heterojunctions. Sensor Actuat A-Phys 207 (2014) 61-66.

[12] D.T. Phan, G.S. Chung, Fabrication and characteristics of a surface acoustic wave UV sensor based on $\mathrm{ZnO}$ thin films grown on a polycrystalline 3C-SiC buffer layer, Curr Appl Phys 12 (2012) 521-524.

[13] M.A. Abbasi, Z.H. Ibupoto, A. Khan, O. Nur, M. Willander, Fabrication of UV photodetector based on coral reef like p-NiO/n-ZnO nanocomposite structures, Mater Lett 108 (2013) $149-152$.

[14] Z. Yuan, A photodiode with high rectification ratio and low turn-on voltage based on $\mathrm{ZnO}$ nanoparticles and SubPs planar heterojunction, Physica E 56 (2014) 160 -164.

[15] Y. Liu, G. Li, R. Mi, C. Deng, P. Gao, An environment-benign method for the synthesis of $\mathrm{p}-\mathrm{NiO} / \mathrm{n}-\mathrm{ZnO}$ heterostructure with excellent performance for gas sensing and photocatalysis, Sensor Actuat B-Chem 191 (2014) 537-534.

[16] L.T. Hoa, H.N. Tien, S.H. Hur, A highly sensitive UV sensor composed of 2D NiO nanosheets and 1D $\mathrm{ZnO}$ nanorods fabricated by a hydrothermal process, Sensor Actuat A-Phys 207 (2014) 20-24.

[17] B.O. Jung, Y.H. Kwon, D.J. Seo, D.S. Lee, H.K. Cho, Ultraviolet light emitting diode based on p-NiO/n-ZnO nanowire heterojunction, J Cryst Growth 370 (2013) 314-318.

[18] S.Y. Tsai, M.H. Hon, Y.M. Lu, Fabrication of transparent p-NiO/n-ZnO heterojunction devices for ultraviolet photodetectors, Solid state Electron 63 (2011) 37-41.

[19] A. Chrissanthopoulos, S. Baskoutas, N. Bouropoulos, V. Dracopoulos, P. Poulopoulos, S.N. Yannopoulos, Synthesis and characterization of $\mathrm{ZnO} / \mathrm{NiO} \mathrm{p}-\mathrm{n}$ heterojunctions: $\mathrm{ZnO}$ nanorods grown on $\mathrm{NiO}$ thin film by thermal evaporation, Photonic Nanostruct 9 (2011) 132-139.

[20] L. E. Greene, M. Law, D. H. Tan, M. Montano, J. Goldberger, G. Somorjai, General route to vertical $\mathrm{ZnO}$ nanowire arrays using textured $\mathrm{ZnO}$ seeds, Nano Lett 5 (2005) 1231-6.

[21] V. Khranovskyy, R. Yakimova, F. Karlsson, P.O. Holtz, Z. N. Urgessa, O.S. Oluwafemi, J.R. Botha, Comparative PL study of individual ZnO nanorods, grown by APMOCVD and CBD techniques, Physica B 407 (2012) 1533. 
[22] V. Khranovskyy, I. Tsiaoussis, L. Hultman, R. Yakimova, Selective homoepitaxial growth and luminescent properties of ZnO Nanopillars, Nanotechnology 22 (2011) 185603.

[23] V. Khranovskyy, G.R. Yazdi, G. Lashkarev, A. Ulyashin, R. Yakimova, Investigation of $\mathrm{ZnO}$ as a perspective material for photonics, Physica Status Solidi A 205 (2008) 144-149.

[24] V. Khranovskyy, V. Lazorenko, G. Lashkarev, R. Yakimova, Luminescence anisotropy of ZnO microrods, J Lumin 132 (2012) 2643-2647.

[25] N. H. Alvi, M. Riaz, G. Tzamalis, O. Nur, M. Willander, Fabrication and characterization of high-brightness light emitting diodes based on $\mathrm{n}-\mathrm{ZnO}$ nanorods grown by a low-temperature chemical method on p-4H-SiC and p-GaN, Semicond Sci Technol 25 (2010) 065004.

[26] A. Echresh, M. Zargar Shoushtari, M. Farbod, Effect of growth angle and post-growth annealing on the structural and optical properties of $\mathrm{ZnO}$ nanorods grown hydrothermally on $\mathrm{p}$ Si substrate, Mater Lett 110 (2013) 164-167.

[27] Z.G. Yang, L.P. Zhu, Y.M. Guo, W. Tian, Z.Z. Ye, B.H. Zhao, Valence-band offset of p$\mathrm{NiO} / \mathrm{n}-\mathrm{ZnO}$ heterojunction measured by X-ray photoelectron spectroscopy, Phys Lett A 375 (2011) 1760-63.

[28] B. Zhao, X.K. Ke, J.H. Bao, C.L. Wang, L. Dong, Y.W. Chen, H.L. Chen, Synthesis of flower-like NiO and effects of morphology on its catalytic properties, J Phys Chem C 113 (2009) 14440-14447.

[29] T.A. Dar, A. Agrawal, P. Mirsa, L.M. Kukreja, P.K. Sen, P. Sen, Valence and conduction band offset measurements in Ni0.07Zn0.93O/ZnO heterostructure, Curr Appl Phys 14 (2014) 171-175.

[30] Z. Yuan, A photodiode with high rectification ratio and low turn-on voltage based on $\mathrm{ZnO}$ nanoparticles and SubPc planar heterojunction, Physica E 56 (2014) 160-164.

[31] L.W. Ji, S.M. Peng, Y.K. Su, S.J. Young, C.Z. Wu, W. B. Cheng, Ultraviolet photodetectors based on selectively grown ZnO nanorod arrays, Appl Phys Lett 94 (2009) 203106-203108.

[32]X. Gu, M. Zhang, F. Meng, X. Zhang, Y. Chen, S. Ruan, Influences of different interdigital spacing on the performance of UV photodetectors based on ZnO nanofibers, Appl Surf Sci 307 (2014) 20-23. 
[33] J. Zhou, Y. Gu, Y. Hu, W. Mai, P. H. Yeh, G. Bao, A. K. Sood, D. L. Polla, Z. L.Wang, Gigantic enhancement in response and reset time of ZnO UV nanosensor by utilizing Schottky contact and surface functionalization, Appl Phys Lett 94 (2009) 191103-191105.

[34] M. Tyagi, M. Tomar, V. Gupta, Fabrication of an efficient Glad-assisted p-NiO nanorods/n-ZnO thin film heterojunction UV photodiode, J Mater Chem. C 2 (2014) 2387-2393. 
Table 1. XPS CL spectra fitting results and VBM positions in $\mathrm{ZnO}$ nanorods, $\mathrm{NiO}$ thin film and $\mathrm{p}-\mathrm{NiO} / \mathrm{n}-\mathrm{ZnO}$ heterojunction.

\begin{tabular}{|c|c|c|}
\hline Sample & State & Binding energy \\
\hline ZnO nanorods & $\begin{array}{c}\mathrm{Zn} 2 \mathrm{p}_{3 / 2} \\
\mathrm{O} 1 \mathrm{~s} \\
\mathrm{VBM}\end{array}$ & $\begin{array}{c}1022.34 \pm 0.05 \mathrm{eV} \\
531.08 \pm 0.05 \mathrm{eV} \\
3.04 \pm 0.05 \mathrm{eV}\end{array}$ \\
\hline NiO thin film & $\begin{array}{c}\mathrm{Ni} 2 \mathrm{p}_{3 / 2} \\
\mathrm{O} 1 \mathrm{~s} \\
\mathrm{VBM}\end{array}$ & $\begin{array}{c}853.65 \pm 0.05 \mathrm{eV} \\
529.32 \pm 0.05 \mathrm{eV} \\
0.61 \pm 0.05 \mathrm{eV}\end{array}$ \\
\hline p-NiO/n-ZnO heterojunction & $\begin{array}{l}\text { Zn } 2 p_{3 / 2} \\
\text { Ni } 2 p_{3 / 2}\end{array}$ & $\begin{array}{c}1021.83 \pm 0.05 \mathrm{eV} \\
854.07 \pm 0.05 \mathrm{eV}\end{array}$ \\
\hline
\end{tabular}

Table 2: The turn-on voltage $\left(\mathrm{V}_{\mathrm{T}}\right)$, current under forward bias $\left(\mathrm{I}_{\mathrm{F}}\right)$, under reverse bias $\left(\mathrm{I}_{\mathrm{R}}\right)$, ideality factor $(\mathrm{n})$ and reverse bias saturation current $\left(\mathrm{I}_{\mathrm{sat}}\right)$.

\begin{tabular}{ccccccc}
\hline & $\mathbf{V}_{\mathbf{T}}(\mathbf{V})$ & $\mathbf{I}_{\mathbf{F}}(\mathbf{A})$ & $\mathbf{I}_{\mathbf{R}}(\mathbf{A})$ & $\mathbf{I}_{\mathbf{F}} / \mathbf{I}_{\mathbf{R}}$ & $\mathbf{n}$ & $\mathbf{I}_{\mathbf{s a t}}(\mathbf{A})$ \\
\hline Dark & 4.5 & $8.85 \times 10^{-5}$ & $1.47 \times 10^{-6}$ & 60.11 & 6.9 & $1.24 \times 10^{-9}$ \\
UV light & 4.1 & $5.28 \times 10^{-4}$ & $5.59 \times 10^{-6}$ & 94.47 & - & - \\
\hline
\end{tabular}



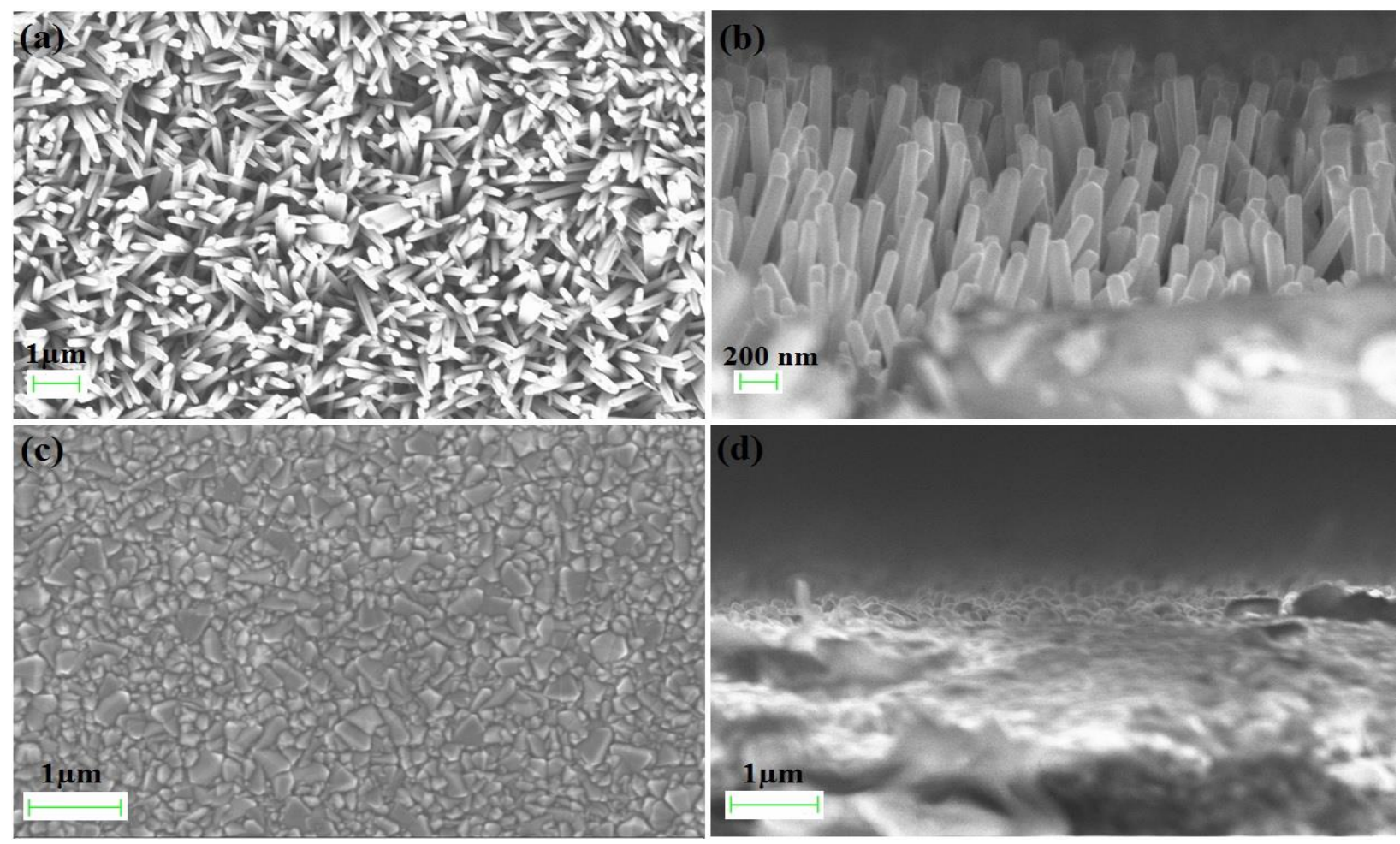

Figure 1: Top view and cross section SEM images of $\mathrm{ZnO}$ nanorods $(\mathrm{a}, \mathrm{b})$ and $\mathrm{NiO}$ thin film/ZnO nanorods heterojunction (c, d). 

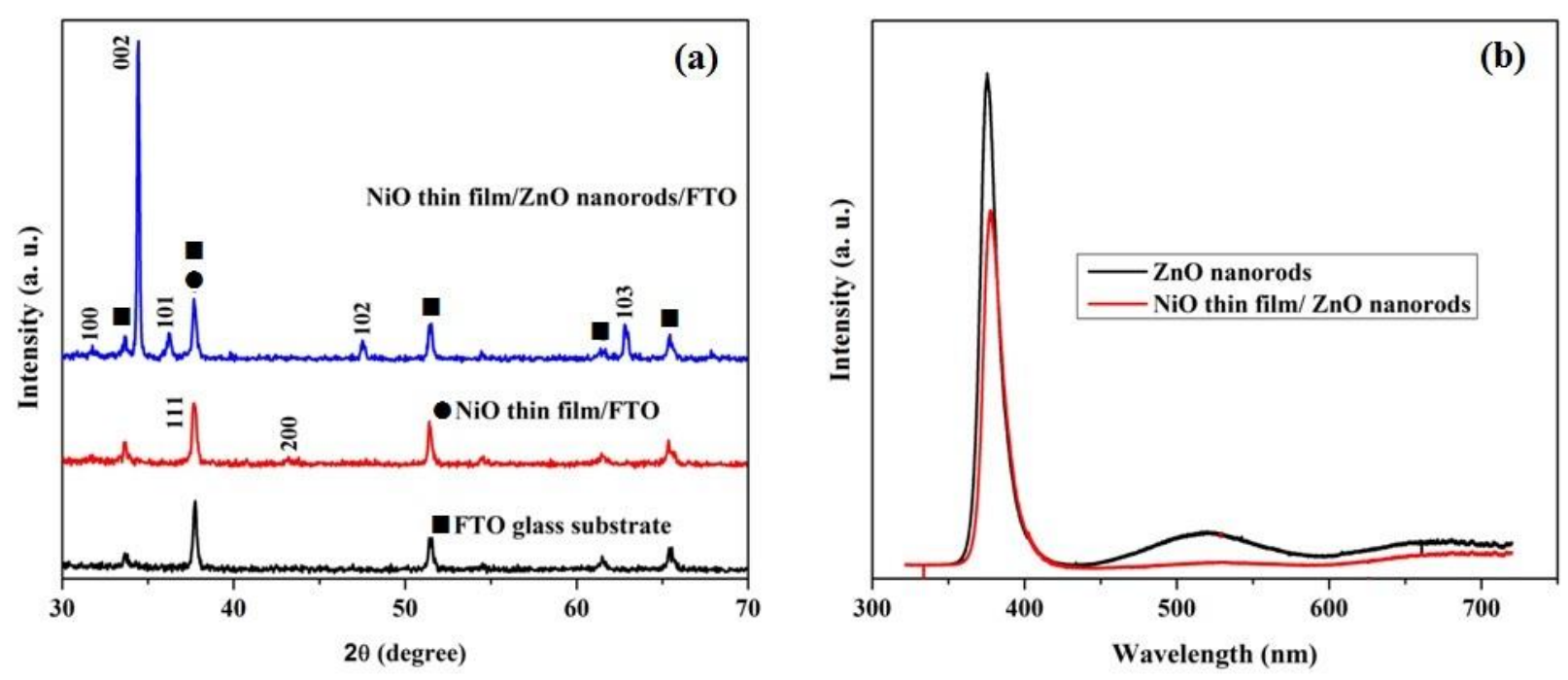

Figure 2: (a) XRD pattern of $\mathrm{NiO}$ thin film/ $\mathrm{ZnO}$ nanorods heterojunction and (b) room temperature PL spectra of $\mathrm{ZnO}$ nanorods and $\mathrm{NiO}$ thin film/ZnO nanorods heterojunction. 

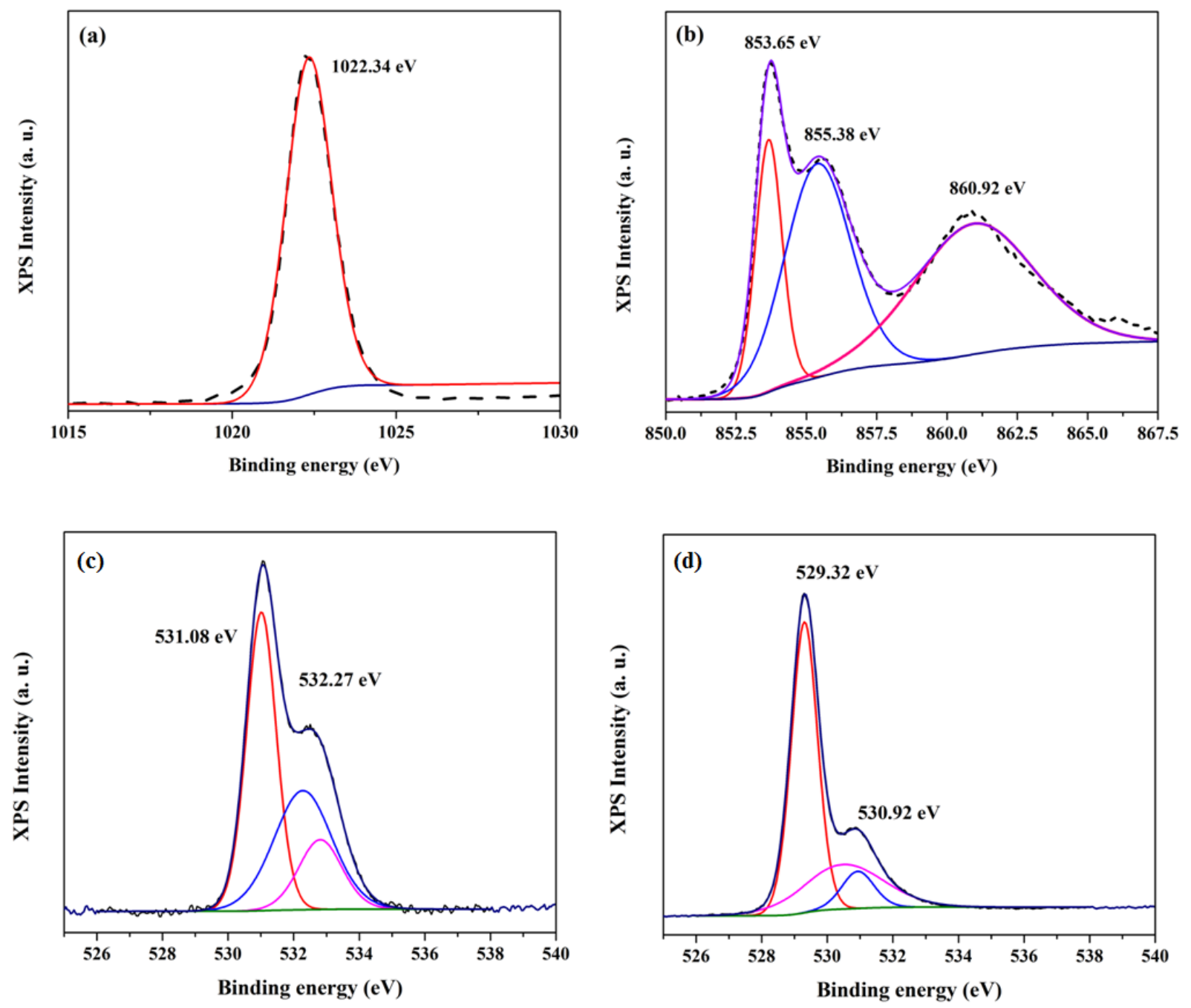

Figure 3. CL spectra of (a) $\mathrm{Zn} 2 \mathrm{p}_{3 / 2}$, (c) $\mathrm{O} 1 \mathrm{~s}$ in $\mathrm{ZnO}$ nanorods and (b) $\mathrm{Ni} 2 \mathrm{p}_{3 / 2}$, (d) $\mathrm{O}$ 1s in $\mathrm{NiO}$ thin film. 

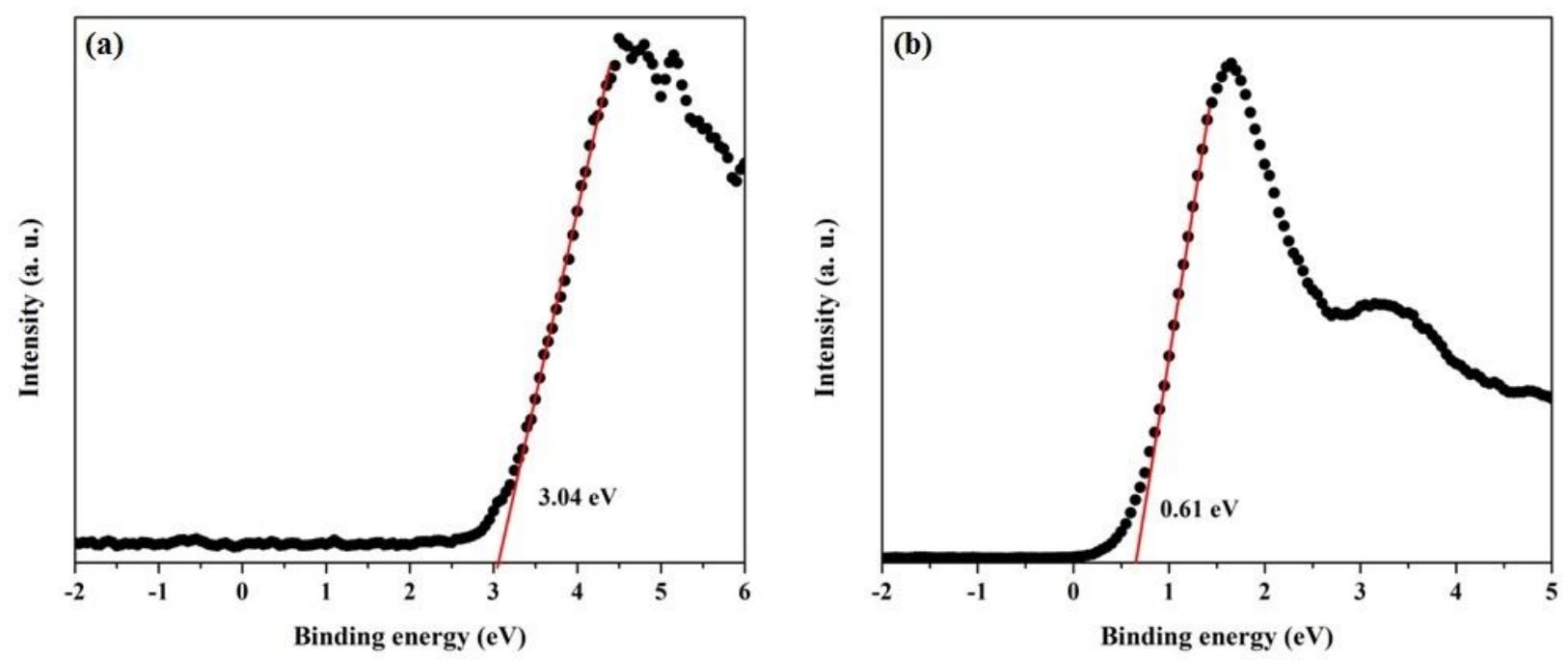

Figure 4. Valence band edge spectra of (a) $\mathrm{ZnO}$ nanorods, and (b) $\mathrm{NiO}$ thin film. 

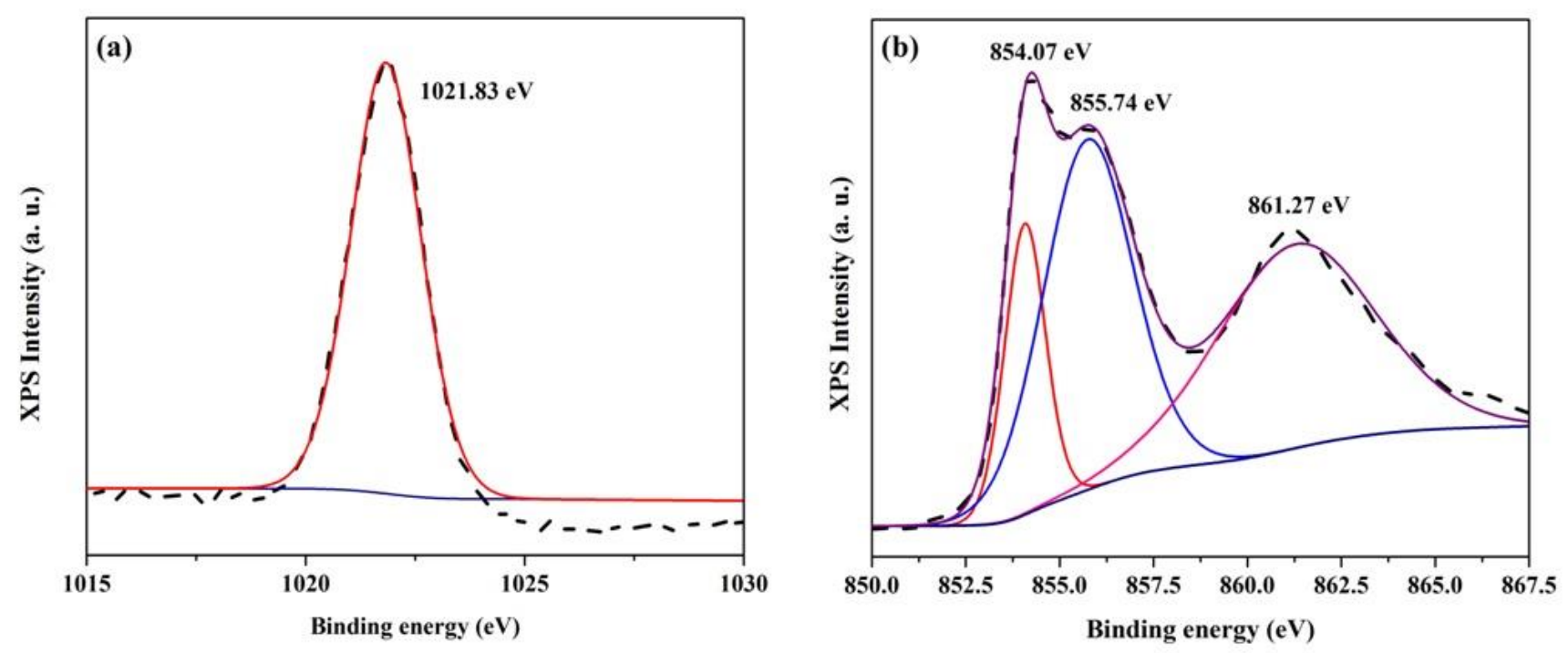

Figure 5. CLs of (a) $\mathrm{Zn} 2 \mathrm{p}_{3 / 2}$ and (b) $\mathrm{Ni} 2 \mathrm{p}_{3 / 2}$ in $\mathrm{NiO}$ thin film/ZnO nanorods heterojunction. 


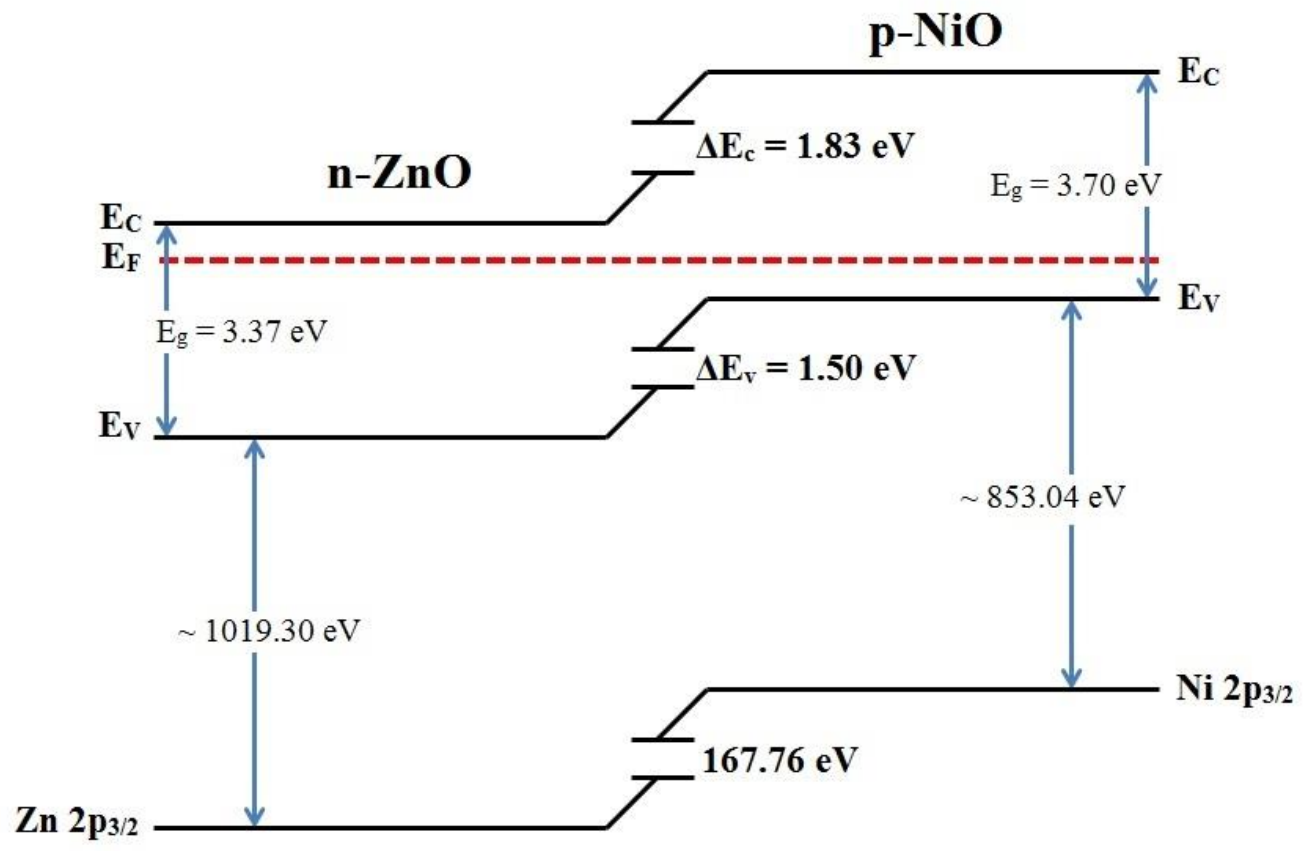

Figure 6. Schematic diagram of the band alignment of the $\mathrm{p}-\mathrm{NiO} / \mathrm{n}-\mathrm{ZnO}$ heterojunction. 
(a)
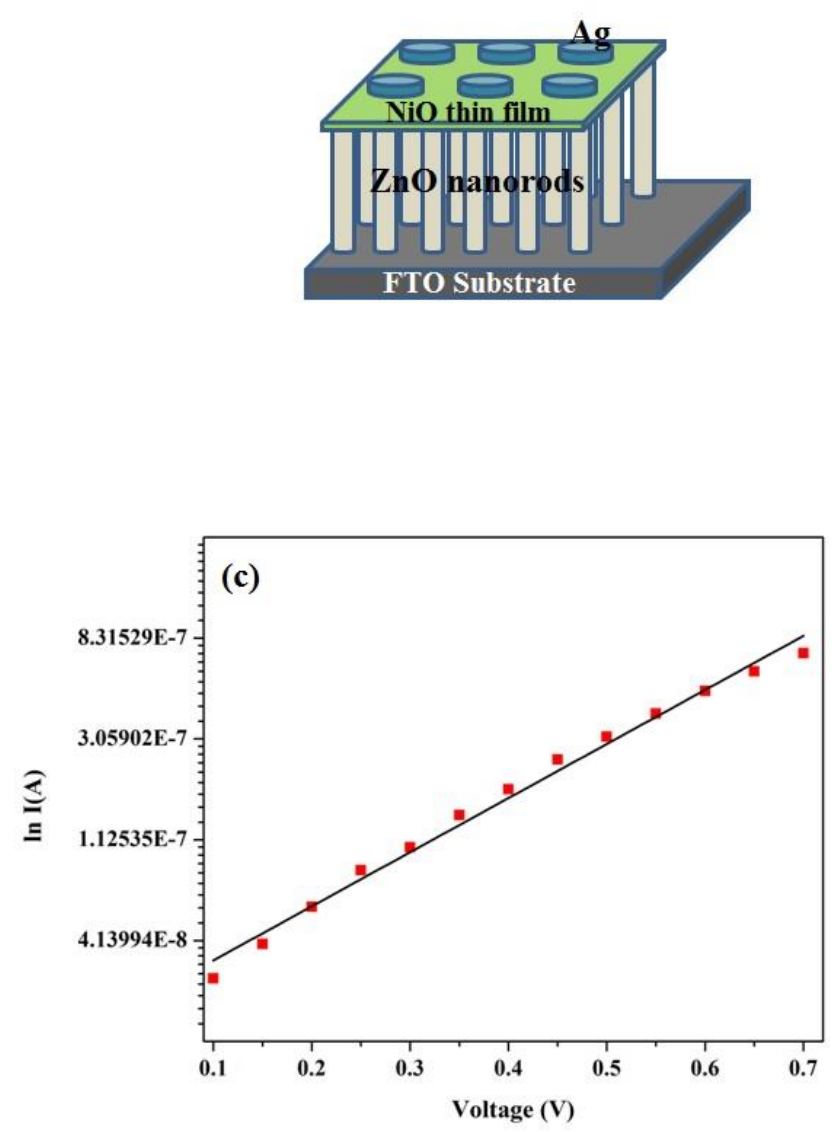
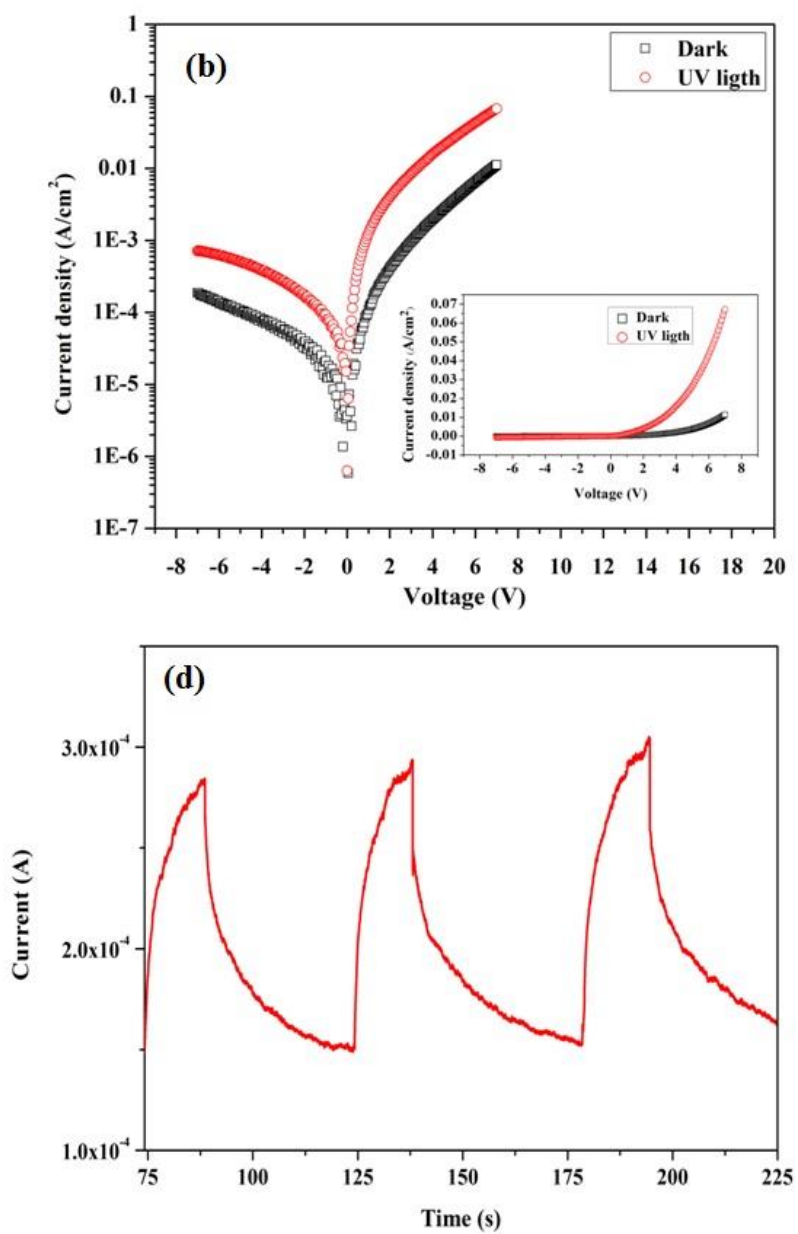

Figure 7: (a) Schematic diagram of the $\mathrm{p}-\mathrm{NiO}$ thin film/n-ZnO nanorods heterojunction, (b) Semilog Current density - voltage characteristics of $\mathrm{p}-\mathrm{NiO} / \mathrm{n}-\mathrm{ZnO}$ heterojunction, (Inset shows the Current density-voltage characteristic of heterojunction), (c) the plot of $\ln$ (I) versus $\mathrm{V}$ to extraction ideality factor, and (d) the diode photo response of the $\mathrm{p}-\mathrm{NiO} / \mathrm{n}-\mathrm{ZnO}$ heterojunction. 